\title{
Correction: P117 Neutrophil chemotaxis in the sz form of alpha-1 antitrypsin deficiency
}

Vayalapra S, McGuinness AJA, Stockley RA, et al. P117 Neutrophil chemotaxis in the sz form of alpha-1 antitrypsin deficiency. Thorax 2017;72:A146-7. doi:10.1136/ thoraxjnl-2017-210983.259.

The correct author list for this paper should be the following:

S Vayalapra, ${ }^{1}$ A J A McGuinness, ${ }^{2}$ E Sapey, ${ }^{2}$ R A Stockley, ${ }^{2}$ A M Turner ${ }^{2}$

${ }^{1}$ College of Medical and Dental Sciences, University of Birmingham, Birmingham, UK

${ }^{2}$ University Hospitals Birmingham, Birmingham, UK

(c) Article author(s) (or their employer(s) unless otherwise stated in the text of the article) 2018. All rights reserved. No commercial use is permitted unless otherwise expressly granted.

Thorax 2018;73:400. doi:10.1136/thoraxjnl-2017-210983.259corr1

D) Check for updates 